\title{
Jornalismo e Ciências Sociais: circulação de saberes sobre o presente
}

\section{Christa Berger}

Doutora; Universidade do Vale do Rio do Sinos christab177@gmail.com

\section{Resumo}

Este artigo se dedica a discorrer sobre o Jornalismo e suas relações com campos sociais, memórias e acontecimentos. Apresentam-se argumentos a respeito das mudanças na sociedade contemporânea e demonstra-se que, como consequência, as narrativas jornalísticas atuais acabam constituindo-se como objeto de interesse das Ciências Sociais Aborda-se a compreensão acerca dos saberes produzidos nos discursos jornalísticos por intermédio de interpretações de cientistas sociais e aponta-se a amplitude de tal fato. Há o uso de matérias, reportagens e programas de televisão como recursos para exemplificar apreciações por cientistas sociais, principalmente, no que se refere ao que a mídia transmitia a respeito das manifestações de junho de 2013.

\section{Palavras-chave}

Jornalismo. Ciências Sociais. Campos Sociais. Memórias. Acontecimentos.

\section{Introdução}

Este texto resulta de um convite para participar da edição comemorativa da revista Intexto, pela passagem dos 20 anos do Programa de Pós Graduação em Comunicação e Informação da UFRGS. A natureza da publicação, associada a um evento de rememoração, de certo modo, autoriza que eu me inclua no texto, uma vez que, nesse programa, iniciei meu percurso como professora/pesquisadora de um PPG.

Eu acabara de defender minha tese de doutorado Campos em confronto: a terra e o texto, em que expunha a relação entre o Jornalismo e o Movimento dos Trabalhadores Sem Terra (MST), observando a cobertura que o jornal Zero Hora fazia deste movimento e de como o MST buscava estratégias de visibilidade. Eu estudei acontecimentos produzidos pelo 
MST e a passagem deles para as páginas do jornal na condição de acontecimentos jornalísti$\cos$.

Três conceitos, na tese apenas intuídos, norteiam meu trabalho desde então - a noção de campos sociais, de memória e de acontecimento -, tendo, como principal motivação, a de observar movimentos e relações, reconhecer o que está entre um e outro; entre a sociedade e o Jornalismo; entre acontecimentos e coberturas jornalísticas; entre o cinema, a literatura, a história e o Jornalismo; entre a redação de jornal e a universidade. Convencida de que a teoria da prática de Pierre Bourdieu $(1983,1987,1996)$ oferece direção para a pesquisa, seja porque relaciona conceitos (campo/habitus/capital), seja porque dá sentido à longa tradição de afirmação de que o "real é relacional" e que ele é visível por meio de um protocolo de pesquisa racional.

O projeto que desenvolvo, atualmente, problematiza a relação entre Jornalismo e Ciências Sociais. Ele dá continuidade ao trabalho de observar o modo de o Jornalismo lidar com memórias traumáticas, especificamente, sobre coberturas que dizem respeito ao golpe militar de 1964 no Brasil e a ditadura que lhe seguiu, em diálogo com narrativas cinematográficas e culturais que também se ocupam da questão.

O objetivo que persigo é o de compreender os desdobramentos dos saberes produzidos pelo discurso jornalístico, a partir das interpretações que cientistas sociais oferecem para a vida na sociedade contemporânea. Encontrei, cada vez mais, em livros de estudiosos da sociedade, fragmentos de matérias jornalísticas, observações de coberturas, fatos tratados por jornalistas ora para ilustrar uma ideia, para dar sentido a um argumento, para oferecer uma interpretação do funcionamento da sociedade. Zygmunt Bauman (2010; 2011), Tzvetan Todorov (2012) e Slavoj Zizek (2011) são exemplares para confirmar a impressão.

Se a Sociologia e o Jornalismo têm afinidades históricas que já foram observadas muitas vezes, me aproprio da visão de José de Souza Martins para explicar o tipo de confluência que se manifesta, por ora. E, com isso, tentar encontrar algumas razões para tanto.

No livro A sociabilidade do homem simples (2008), Martins dedica um capítulo à vida cotidiana. 0 mesmo argumenta que a introdução desta temática nas Ciências Sociais s está relacionada com (1) o refluxo das esperanças da humanidade num mundo novo de justiça, de liberdade e de igualdade; (2) uma descrença na História, uma renúncia à ideia de que o homem é senhor de sua história, de que pode produzir seu próprio destino; (3) o ceticismo decorrente das desilusões que tem acompanhado a notável capacidade de autorregeneração da sociedade capitalista. Nesse sentido, 
A vida cotidiana se tornou um refúgio para o desencanto de um futuro improvável, de uma História bloqueada pelo capital e pelo poder. Viver o presente já é uma consigna que encontra eco numa sociologia do detalhe, do aqui e hoje, do viver intensamente o minuto desprovido de sentido, que poderia ser definida como sociologia pós-moderna (MARTINS, 2008, p. 51).

0 interesse pela vida cotidiana, em tal perspectiva, remete a um mundo em transformação. No limite, um mundo em crise:

\begin{abstract}
As grandes certezas terminaram. É que, com elas, entraram em crise as grandes estruturas da riqueza e do poder (e também os grandes esquemas teóricos). Daí decorrem os desafios deste nosso tempo. Os desafios da vida e os desafios da ciência, da renovação do pensamento sociológico. Se a vida de todo o dia se tornou o refúgio dos céticos, tornou-se igualmente o ponto de referência das novas esperanças da sociedade. 0 novo herói da vida é o homem comum imerso no cotidiano. É que no pequeno mundo de todos os dias está também o tempo e o lugar da eficácia das vontades individuais, daquilo que faz a força da sociedade civil, dos movimentos sociais (MARTINS, 2008, p. 52).
\end{abstract}

Ao Jornalismo sempre coube o pequeno mundo de todos os dias, bem como as histórias do homem comum. Esse é o conhecimento que cabe à produção jornalística. Aqui, relembro Park (2008), que trata o conhecimento deste pequeno mundo como acquaintance with (saber algo acerca de), e a notícia deste pequeno mundo é, para ele, a forma elementar de conhecimento. 0 conhecimento da realidade de todo o dia era desqualificado ou, até, recusado pelas Ciências Sociais em nome, justamente, de seu "suposto desencontro com a História" (MARTINS, 2008, p. 53). A Sociologia da vida cotidiana, para Martins, diverge da orientação teórica de marxistas e fenomenologistas justo pelo encontro com o conhecimento do senso comum na vida cotidiana e, de igual modo, na História.

Reconhecer, no entanto, o lugar da vida cotidiana e do senso comum nos deslocamentos de interesse da Sociologia, que abandona os grandes temas da revolução e da ruptura para dar conta da continuidade e da rotina, não significa uma associação imediata com o Jornalismo. Pelo menos sociólogos e jornalistas não fazem este continuum. Mas há nas narrativas de um e outro, pontos de contato que vale reconhecer.

José de Souza Martins traz exemplos, nesse livro, da realidade brasileira para refletir sobre a vida cotidiana. Mas ele não só omite a fonte de sua informação como não inclui o Jornalismo como um elemento de composição da vida cotidiana e de exposição do senso comum do homem simples. Para mim, no entanto, os exemplos trazidos por ele estão enunciados como se fossem acontecimentos jornalísticos, o que só confirmaria que acontecimen- 
tos e acontecimentos jornalísticos quase não se distinguem para o observador da vida em sociedade. Diz ele:

0 acontecimento e a circunstância não constituem um recorte arbitrário nas recorrências da vida social. Eles constituem adensamentos problemáticos, momentos de impasse em que as contradições profundas e ocultas não podem mais ser contidas e ocultadas. Por isso, enredam os viventes na trama do acontecimento, que pode ser dramático ou trágico. Foi o caso do operário que planejara matar os patrões e acabou matando a mulher que amava (e seu marido), a mulher de um amor impossível (MARTINS, 2008, p. 138).

E continua, alguns parágrafos depois:

[...] Nesse caso, as contradições e tensões se expressaram como ambiguidade e loucura e as oposições e os conflitos das classes sociais apareceram como amor e ódio, comunidade e conflito. 0 assassinato detonou as circunstâncias da vida do operário e do patrão, suburbana, nem rural nem urbana, revelando suas camadas, suas diferentes e combinadas verdades. A historicidade do conflito social se apresentou como tragédia: o caso nos revelou os impossíveis das relações de classe e, ao mesmo tempo, os impasses e bloqueios da História ao lado dos possíveis, ainda fragilizados por uma História que, naquele momento, não podia ser vivida senão como indefinição, incerteza (MARTINS, 2008, p. 138).

Aqui, o pequeno herói, protagonista de uma tragédia que o Jornalismo enquadra como "crime passional", fruto do destino azarado desses indivíduos, recebe uma camada de sentido no contexto das relações de classe, entre o urbano e o rural, que traz angústia e incertezas. Um estudioso de gênero acrescentaria outra camada: a de que a dominação se exerce sempre mediante violência. No caso, se trata da dominação masculina.

A razão de ser do Jornalismo é, justamente, a vida em estado latente, são os heróis, grandes e pequenos. 0 episódico e o circunstancial são de interesse dos leitores e é do contrato com eles que se nutre o Jornalismo. Ele se ocupa da atualidade, desta temporalidade inscrita em um tempo alargado, que vem de um antes e que dá a ver o depois. Na narrativa jornalística, a atualidade precisa da ancoragem no passado e não pode prescindir de sinalizar futuros possíveis. 0 fragmento de vida com o qual o Jornalismo se ocupa tem dimensão histórica, apesar de os jornalistas não terem consciência dessa dimensão incluída em sua produção diária. Os jornalistas, como narradores privilegiados do cotidiano, desenvolvem habilidades e detêm métodos para captar os acontecimentos que mobilizam o imaginário de seus leitores, o que dá aos acontecimentos jornalísticos o estatuto de "visão hegemônica de uma determinada época" ou por onde circulam ecos do "espírito do agora".

O Jornalismo, como lugar da narrativa do presente e da vida cotidiana, ficou por muito tempo relegado a um plano secundário por quem desejava estudar grandes processos soci- 
ais. No máximo, serviu de inspiração aos romancistas. Basta lembrar os livros que inauguraram o gênero: Ilusões Perdidas, de Honoré Balzac, escrito entre 1835 e 1848, ou Bel Ami, de Guy de Maupassant, publicado em 1885. Ou, ainda, como uma fonte documental para o estudioso da História, e, aqui, os exemplos são muitos.

Mudanças substantivas na sociedade contemporânea, que implicam uma convivência mais aproximada entre o vivido, o registrado e o estudado e um interesse maior pela vida cotidiana, redirecionam o lugar do Jornalismo no campo do pensamento intelectual.Se a vida cotidiana passa a ser matéria-prima da Sociologia, como afirma José de Souza Martins, e os jornais produzem conhecimento acerca deste pequeno mundo, é compreensível que as narrativas jornalísticas integrem, por conseguinte, o campo de interesse das Ciências Sociais. Jornalistas e cientistas sociais em temporalidades e metodologias distintas comungam de um mesmo objetivo, que pode ser assim sintetizado: narrar o presente, com uma narrativa capaz de tornar os que os escutam, mais esclarecidos. Os jornalistas devem fazer emergir os acontecimentos e suas circunstâncias, mostrar ações e reações que se repetem até à exaustão, mostrar o que apenas se insinua; os cientistas sociais devem interpretar os mesmos acontecimentos, dotando-os de camadas de sentidos, e ler os sintomas para reconhecer o que se agita nos subterrâneos da sociedade.

Ao cobrir os acontecimentos da atualidade, o Jornalismo produz um conhecimento da vida cotidiana reconhecendo o que move a política, a economia, a cultura e, ainda, o que fica na sombra destas grandes temáticas. A mediação fundamental da historicidade da vida cotidiana se encontra, portanto, no Jornalismo, e é esta condição que alguns cientistas sociais percebem e incorporam em suas tentativas de capturar o tempo presente, tornando mais ou menos visível a inclusão de fragmentos jornalísticos para dizer dos conteúdos e dos modos de narrar que circulam hegemonicamente na sociedade.

Apresentei, no texto Notícias do Brasil (BERGER; ALMEIDA, 2014), um exemplo do aproveitamento de notícias, neste caso, do noticiário de Economia para explicar a crise do capitalismo globalizado. Giuseppe Cocco, na Aula Magna que proferiu na Escola de Governo do Rio Grande do Sul, em 2013, toma uma edição do jornal Folha de São Paulo para fazer uma análise que, ao mesmo tempo em que descreve densamente a crise do Estado e as fissuras nas relações entre capital e trabalho no capitalismo globalizado, também permite observar o potencial da narrativa jornalística para explicar a sociedade. A leitura do maior número possível de jornais, já na introdução da palestra, é recomendada pelo professor como uma das melhores maneiras de se informar. Na Folha de São Paulo, de oito de maio daquele 
ano, ele encontra matérias "[...] extremamente interessantes para ter uma ideia de como é o mundo em que nós estamos." (informação verbal)ํ․ Cocco não desconsidera o caráter ideológico do jornal, mas acredita que ele seja "sério e analítico" quando o assunto é o regime de acumulação. Entre os materiais escolhidos, estão um artigo sobre a intenção do dono da Avianca de comprar a TAP; uma entrevista com o chefe italiano do Citi Transaction Service, setor do americano CitiGroup; e uma entrevista com um indiano em visita ao Brasil. Conteúdos bastante diversificados, e que, na perspectiva de Cocco, dão uma boa mostra de como a produção mundial está organizada atualmente. A tese articuladora é que a globalização, na reorganização do capitalismo para enfrentar a crise do Estado, desenvolveu-se ao longo de três linhas: a primeira é a financeirização (desde o cartão de crédito); a segunda é a revolução antiburocrática (condições de governabilidade); e, a terceira, é a industrialização flexível, japonesa (desintegração vertical). Os exemplos retirados da Folha de São Paulo foram o modo de o conferencista mostrar como funcionam esses aspectos da globalização.

Não é de hoje que o Jornalismo e a Sociologia mantêm relações. Ora são lembradas como saberes que lidam com o conhecimento, ora é o sociólogo que foi repórter, ora é o jornalista que vai a campo com as ferramentas do cientista.

Um registro importante desta relação e, talvez, o primeiro, é o projeto de estudo que Max Weber apresentou no Primeiro Congresso dos Sociólogos Alemães, em 1910, infelizmente não concretizado. No texto, Weber argumenta que o Jornalismo é um objeto de estudo para a Sociologia, sugerindo, inclusive, uma linha de pesquisa acerca dele. Weber inicia, assim, sua conferência: "Senhores, o primeiro tema que a Associação Alemã de Sociologia considerou adequado para um estudo genuinamente científico é uma Sociologia da Imprensa." (2006, p. 34).

0 poder da imprensa, diz Max Weber, ao justificar a importância de tal investigação, advém da sua condição de transformar determinadas questões, que ela escolheu, em tema público, e por poder manter no anonimato as razões da escolha e as fontes da informação. Considera que a imprensa é uma empresa capitalista e privada com uma posição peculiar, diferente das outras empresas por ter dois tipos de clientes, os anunciantes e os leitores. Outra questão a considerar, sublinha-se, são as influências, até, mesmo, consequências, sobre o cérebro, por ter o homem moderno se acostumado a uma caçada a todos os campos da vida, da cultura, da política, antes mesmo de se alimentar.

${ }_{1}^{1}$ Proferida pelo Prof. Dr. Giuseppe Cocco, palestrante da Aula Magna Rede Escola de Governo, em março de 2013. 
Caso o projeto tivesse sido realizado, teria surgido, aí, uma orientação para a pesquisa em Sociologia do Jornalismo, pois abarcava todas as instâncias que, ainda hoje, interessam: a conformação dos monopólios, os critérios de noticiabilidade e a relação com os anunciantes, com as fontes e com os leitores.

Deve-se relembrar, também, o nome de Robert Park, jornalista que dirigiu sua atenção, como repórter, aos temas que mais tarde elegeria como suas questões de investigação. Em seus textos, Park manifestou, muitas vezes, as coincidências entre as duas profissões:

O sociólogo é um tipo de super-repórter, como os homens que escreviam no Fortune. 0 sociólogo conta as coisas de uma forma um pouco mais precisa, e com um estilo um pouco mais imparcial que o homem médio: o que meu amigo Franklin Ford chamaria as grandes notícias (BERGANZA CONDE, 2008, p. 19).

As grandes notícias, nas palavras de Park, constituíam a análise "[...] das tendências durante um longo período de tempo, referem-se ao que está acontecendo no presente, não relatam somente o que sucede na superfície das coisas e explicam aquilo que parece que está passando." (BERGANZA CONDE, 2008, p. 19). As grandes notícias seriam a forma de fazer Jornalismo em profundidade, mas, também, a visão parkiana de como se deve fazer investigação sociológica. Ou seja, desponta o sentido que ele percebia entre estas duas formas de conhecimento e que orientam seu pensamento na construção da sociologia do conhecimento. Maria Rosa Berganza Conde (2000) estudou Park em sua tese de doutorado e conta que ele, Ford e Dewey lançaram, em 1892, um projeto jornalístico que não teve êxito, a publicação do Thought news, "[...] um jornal que deveria interpretar os acontecimentos diários a partir de uma perspectiva sociológica." (p. 14).

Os anos de Jornalismo ofereceram a Park a possibilidade de construir um pensamento sobre as formas de conhecimento, expondo os dois tipos clássicos, knowledge about (um conhecimento formal) e acquaintance with (um conhecimento não sistemático, intuitivo ou do senso comum) e, entre os dois, um continuum. Nesse continuum, postula Park, estão as notícias, definidas como uma forma de conhecimento:

No mundo moderno, o papel da notícia tem assumido maior importância em comparação com outras formas de conhecimento, a história por exemplo. As mudanças nos últimos anos têm sido tão rápidas e drásticas que o mundo moderno parece ter perdido sua perspectiva histórica, e parece que nós estamos vivendo dia a dia no que descrevi anteriormente como um "presente precioso". Nessas circunstâncias, a história parece ser lida ou escrita principalmente para nos capacitar, através da comparação do presente com o passado, a entender o que está acontecendo na nossa volta mais do que saber "o que realmente aconteceu", como os historiadores dizem (PARK, 2008, p. 70). 
O continuum pensado por Park, em que a notícia faria a ponte entre os conhecimentos com o objetivo de entender o que está acontecendo a nossa volta, ocorre de uma forma mais acelerada atualmente, pelas condições propiciadas pela tecnologia que permite a simultaneidade entre o acontecido e sua narrativa (no dispositivo jornalístico) e, também, da produção de ensaios em tempo menor. Assim, o "presente precioso", circula da sociedade ao Jornalismo e do Jornalismo aos livros em uma temporalidade sobreposta pelo imediatismo ou simultaneidade em que nos acostumamos a compartilhar as coisas.

\title{
2 Liberdade de expressão
}

Tzvetan Todorov (2012), além de trazer recortes de jornais para exemplificar uma ideia ou elaborar um argumento, ao tratar da democracia e do neoliberalismo, propõe aproximações com o Jornalismo ou a mídia informativa por meio do conceito "liberdade de expressão". A liberdade de expressão é um valor da democracia, é o próprio fundamento dela, pensada, inicialmente, como uma necessidade para o cidadão isolado, maltratado pela administração, diante do qual todas as portas se fecham e a quem só resta um recurso: tornar pública a injustiça de que é vítima, levando-a, por exemplo, aos leitores de um jornal.

Assim posto, no entanto, a questão fica muito simplificada e merece reparos: como, por exemplo, pode-se "Defender a palavra aspirante à liberdade de expressão, para um defensor antissemita, uma propaganda odienta ou uma informação mentirosa?" (p. 138). Quando defendida por um grupo de mídias, diz Todorov, a questão fica, ainda, mais complexa.

\begin{abstract}
A liberdade de expressão certamente tem seu lugar entre os valores democráticos, mas é difícil imaginar como se poderia fazer dela o fundamento comum desses valores. Tal liberdade representa uma exigência de tolerância integral (nada do que se diz pode ser declarado intolerante), e, portanto, um relativismo generalizado de todos os valores. 'Eu reclamo o direito de defender publicamente qualquer opinião, assim como o de denegrir qualquer ideal'. Ora, cada sociedade precisa de uma base de valores compartilhados: substitú́-los por 'eu tenho o direito de dizer tudo o que quiser' não basta para fundamentar uma vida em comum. Evidentemente, o direito de se subtrair a certas regras não pode ser a única regra a organizar a vida de uma coletividade. 'É proibido proibir' é uma bela frase, mas nenhuma sociedade pode limitar-se a ela (TODOROV, 2012, p. 139).
\end{abstract}

Aqui, entram as funções do Estado, pois são essas que vão dizer dos limites à liberdade de expressão - proteger os cidadãos, combater as discriminações, atuar levando em conta a justiça e o bem-estar comuns, defender a dignidade de todos. Se a sociedade democráti- 
ca adere a esses princípios, serão eles a orientar as restrições à liberdade de expressão. Esta, portanto, só ganha sentido em um contexto, e os contextos variam enormemente.

Não é o mesmo contexto, a publicação de uma opinião em um livro, em um artigo de jornal, ou uma intervenção na tevê, e mesmo na televisão não é o mesmo contexto, a emissão em canal aberto às $20 \mathrm{~h}$ e um programa em canal fechado à meia-noite. A ciência e a arte não deveriam ter nenhum impedimento à liberdade de se exprimirem. Mas a palavra pública, pelo poder que detém, deve corresponder a alguns critérios para sua circulação.

Diz Todorov que a livre expressão dos poderosos pode ter consequências funestas para os sem voz e que não basta ter o direito a se expressar, é preciso que a pessoa disponha desta possibilidade- o que não corresponde aos princípios das sociedades desiguais. "Como contrapoder a liberdade de expressão é preciosa, já aliada do poder ela, às vezes, deve ser limitada", complementa o autor.

Todorov trata dos novos meios identificando-os como contrapoder. Ele afirma que houve a percepção, nos países em que as mídias são controladas pelo Estado, de que novos tipos de tecnologia propiciavam o acesso à informação, principalmente por meio das redes sociais, pois estas se esgueiram dos controles centralizados. "Por causa do Facebook e do Twitter, a informação pode circular na China, esquivando-se ao controle do Bureau Político [...]", salienta o autor. Contudo, apesar de Todorov defender que compartilhar informações não é abuso de poder, mesmo que isso derrube governos repressivos, ele adverte:

\begin{abstract}
Em outras circunstancias, porém, o mesmo instrumento pode servir à submissão: se todos os membros da rede repercutirem docilmente a opinião de uma figura dominante, o resultado é um fortalecimento do conformismo, e não uma emancipação diante das ideias preconcebidas. 0 que era meio de libertação nas mãos dos dominados torna-se meio de submissão nas dos dominantes (TODOROV, 2012, p. 146).
\end{abstract}

Logo, "[...] estabelecer limites à liberdade de expressão não significa solicitar a instauração da censura.", esclarece Todorov. 0 que é iminente é que os detentores do poder maior se responsabilizem ao difundir informações e opiniões, que haja comedimento e ponderação sobre o dito, e que, pela mesma razão, "[...] um membro do governo e, sobretudo, seu chefe, deve pesar suas palavras mais do que o líder de um partido já conhecido por suas posições discriminatórias e xenófobas [...]". 0 autor complementa dizendo que

Aqui, a regra parece ser: a liberdade de expressão deve sofrer tanto menos exceções quanto mais fraco for o poder de que se dispõe, pois constitui então um contrapoder; deve ser examinada tanto mais atentamente quanto maior for a posição de força já ocupada pelos que a invocam, pois, 
nesse caso, ela ameaça acarretar um abuso de poder (TODOROV, 2012, p. 148).

\section{Jornadas de junho}

Nas jornadas de junho de 2013, muitas dessas questões estiveram em pauta. Coberturas mereciam restrições desde o entendimento de alguns leitores. Jornalistas exacerbavam em seu "direito de opinião" - que, por expressarem a opinião de seus donos, não passavam de discursos do poder. Mobilizações organizadas pelas redes sociais também produziam discursos de contrapoder.

As jornadas, como expressão da vida cotidiana, promovidas fora das estruturas partidárias tradicionais, configuravam-se como novo, como atualidade para o Jornalismo; e, ao mesmo tempo, claramente inseridas em uma dimensão histórica. 0 que há de novo nesta atualidade é a pergunta que o jornalista se faz. 0 que das manifestações é ruptura e o que é continuidade é a pergunta do cientista social. No jornal, há espaço para responder as duas questões. Rádio, televisão, pequenas notas no jornal dão conta da superfície, que a reportagem e o artigo de opinião destampam para interpretar e aprofundar.

Uma primeira constatação diz que as jornadas de junho de 2013, no Brasil, acompanharam manifestações semelhantes que ocorreram em diversas partes do mundo, e que são reveladoras das transformações sociais em curso em muitas partes do globo. Como todo acontecimento que tem potencialidade histórica, as manifestações expressaram um campo problemático, que, neste caso, está a nos dizer da saturação, do desconforto, da inconformidade, do mal-estar de viver neste modelo de sociedade. Quando Zizek diz, referindo-se às manifestações, "[...] está claro que não vivemos no melhor mundo possível. Os protestos globais devem servir de lembrança ao fato de que temos obrigação de pensar em alternativas." (2013, p. 99), ele está a nos alertar: onde ocorreram manifestações, essas revelaram insatisfações e informaram que é preciso e é possível mudar.

Situação similar já aconteceu em outro momento da história. Fiz esta relação em texto publicado no livro $O$ delírio é um desejo (BERGER, 2014) e que retomo aqui. Ao observar as revoltas estudantis que aconteciam na Argélia, Polônia, Tchecoslováquia, Alemanha Ocidental, Itália, França e Espanha na chamada Primavera de 1968, Edgar Morin perguntava se era mera coincidência ou se a sincronia devia ser considerada como significativa quando acontecem revoltas e manifestações em muitas partes do mundo ao mesmo tempo. Cada revolta se explica pelo seu contexto nacional ou, ao contrário, existe alguma relação expressiva en- 
tre as distintas rebeliões? Morin explora a segunda hipótese e traça uma argumentação que eu quero considerar aqui, inclusive, porque ela é proposta por ele como Notas Metodológicas em um texto escrito em 1968 (MORIN, 2002). Ele diz que se deve, inicialmente, descrever cada revolta, para poder chegar ao que lhes é comum, e o que ele identificou como "em comum", em 1968, foi:

a) os protestos adquiriram um caráter violento;

b) mobilizaram, em um momento dado, grande número de estudantes;

c) apresentaram reivindicações críticas que afetaram o sistema universitário;

d) apresentaram outras reivindicações que dizem respeito ao sistema político e à organização econômico-social da sociedade.

Esses traços comuns permitiram a ele reconhecer, também, que não se tratava de um movimento internacional centralizado desde o ponto de vista organizativo ou unificado ideologicamente e que pudesse, portanto, dispor de um substrato de internacionalidade. Também se deve descartar, diz ele, a hipótese de um complô - uma organização dirigente centralizadora das revoltas.

Se os países são tão diferentes, as reivindicações também o são e não há um movimento internacional a orientar as lutas. 0 que há de comum que permite reconhecer sincronias $\mathrm{e}$ condensá-las na Primavera?

Morin diz que os traços comuns de um devir histórico é que deram Unidade ao Movimento. A categoria sociológica do devir, do que está por ser conquistado explica; para o autor, a busca por mudanças, transformações e rupturas que a micro sociedade estudantil de então pode existencializar, ideologizar, politizar e desejar.

Ao fazê-lo, o mundo estudantil, não somente expôs seus males e suas inquietações, mas expôs os males e as inquietações de nossas sociedades e, às vezes, com maior profundidade, as de nossa civilização. Suas utopias mostram necessidades ainda adormecidas e atrofiadas. (MORIN, 2002, p. 378).

De 2011 em diante, outra onda de manifestações deu início a um novo devir histórico. O Instituto de Pesquisa Economist Intelligence Unit (EIU) catalogou manifestações em mais de 30 países em 2013, algumas iniciadas em anos anteriores, mas seguindo neste ano. Da Primavera Árabe aos movimentos Ocuppy, o mundo vive um boom de protestos, conclui o documento do instituto. Turquia, Grécia, Espanha, Egito, França, Brasil. É pensando nestas manifestações que levanto a hipótese de que, também, agora, o traço que permite fazer analogias entre situações e contextos tão díspares é a aspiração de devir histórico. Não são se- 
melhanças originadas de situações políticas, econômicas ou culturais, também não são as reivindicações pontuais de cada país que permitem encontrar semelhanças. É a disposição, nem sempre formulada com clareza, de que, como diz Sakamoto: a “[...] civilização representada por fuzis, colheitadeiras, motosserras, terno e paletó mais cedo ou mais tarde terá de mudar." (SAKAMOTO, 2013, p. 93).

No Brasil, o Movimento Passe Livre, que fez eclodir a sequência de manifestações e percorreu o país, foi absolutamente inesperado para os políticos e para os jornalistas, e foi difícil enquadrá-lo nos quadros de referência disponíveis para interpretar o que acontecia. Como explicar que um pequeno aumento no preço da passagem faria desabrochar por todo o Brasil protestos promovidos por jovens, até então, identificados como alienados e individualistas? E que, depois de revogado o aumento, os protestos continuassem? Logo, esse não era o único objetivo. Por outro lado, como explicar uma greve, um protesto, uma manifestação que não enuncia claramente suas reivindicações? Esta foi a grande revelação das "Jornadas de Junho". Não tinha uma pauta unificada para levar à negociação, tinha um conjunto de variáveis de muitas matrizes que contribuíam para a tomada das ruas. As manifestações expressavam sentimentos de mal-estar, de desconforto e de anúncio de saturação. As cidades não são amigáveis para viver, a circulação nelas é hostil, o tempo gasto para locomoção é excessivo, a escola não responde ao desejo dos estudantes, a política não responde ao bem comum. E, talvez, um dito não dito a inspirar e orientar o movimento: estamos carentes da experiência de rua, do contato que uma manifestação propicia com o corpo coletivo, de expandir o olhar para além da tela e, talvez, de um desejo de fazer parte da parcela da população que, no mundo afora, afronta os poderes. A potência das ruas é o que surpreendeu a capacidade de interpretação.

Para a análise da Primavera de 68, Morin deu importância ao sistema de comunicação de então, por permitir uma rápida informação-propagação-contaminação que contribuiu para a divulgação das revoltas. "No que se refere aos protestos estudantis, não é impossível que as revoltas de Paris-Nanterre e de Berlim-Oeste (por exemplo) tenham posto em movimento os jovens de Roma e que todas essas revoltas se fomentem objetivamente umas nas outras." (MORIN, 2002, p. 373).

Se, em 1968, a circulação de informações foi importante e temos exemplos da criação de meios de comunicação alternativos, como a rádio Alice na Itália, folhas mimeografadas distribuídas de mão em mão e grafites nos muros das ruas de Paris, nos últimos anos, as potencialidades das redes sociais foram, em todas as análises, enfatizadas como um fator 
determinante para a mobilização dos jovens. Aqui, mais uma possibilidade de esboçar analogias entre as manifestações dos diferentes países dando a elas um "ar de família".

Celulares, facebook e twitter foram dispositivos de articulação e de chamamento para a revolta urbana, no Brasil como em todos os protestos na África, na Europa e na América Latina. Se tais dispositivos foram determinantes para a mobilização e a produção de informação alternativa, não podemos ignorar a centralidade que a tevê, o rádio e o jornal ainda tem na circulação de informação e no enquadramento dos acontecimentos. Ficou evidente a disputa de sentidos, de enfrentamento hostil entre a velha mídia, mídia comercial ou hegemônica e a mídia colaborativa ou contra-hegemônica. Os sentidos disputados ficam incontestáveis na hora de designar os manifestantes: há os pacíficos e os baderneiros que promovem vandalismos. É interessante fazer um quadro comparativo entre as palavras de ordem dos manifestantes e as manchetes dos jornais e as chamadas da tevê.

\section{Palavras de ordem}

"Se a tarifa não baixar, a cidade vai parar, vem, vem pra rua."

"Tem tanta coisa errada, que nem cabe em um cartaz."

"Brasil, educação, saúde e segurança - tudo no padrão FIFA."

"Hoje é dia de mudança. Vem pra rua."

"Eu sou brasileiro, com muito orgulho, com muito amor."

\section{Manchetes de jornais}

"Contra tarifa, manifestantes vandalizam centro e Paulista."

"A marcha da insensatez: manifestantes contra aumento das passagens, no Rio, causam danos ao patrimônio histórico."

"Governo diz que vai ser mais duro contra vandalismo."

"São Paulo sitiada - tropa de choque avança sobre manifestantes e jornalista."

Outro exemplo que diz das posições antagônicas ocupadas por protagonistas e intérpretes das manifestações, foi o programa Roda Viva de 5 de agosto de 2013, com os idealizadores do coletivo Mídia Ninja. Bruno Torturra e Pablo Capilé no centro da roda foram entrevistados por jornalistas e acadêmicos de referência que questionavam o processo de trabalho e o conteúdo da mídia Ninja. Insistia-se na questão do financiamento da produção jornalística, mostrando seu profundo desconhecimento sobre as modalidades alternativas 
de administração coletiva em desenvolvimento no Brasil e das formas de troca que dispensam o dinheiro oficial. As perguntas evidenciavam a posição de defesa da velha mídia comercial e a distância entre as duas perspectivas de olhar o mundo desde o Jornalismo. Na bancada em círculo, os detentores do Jornalismo histórico, assim denominado por eles, não eram capazes de sentir curiosidade e demonstrar prazer em conhecer outro jeito de fazer Jornalismo, presos em seu papel de guardiões do mundo como ele está, enquanto os dois ocupantes do centro da roda representavam, talvez, um devir jornalístico de acordo com o devir histórico em ebulição.

As posições divergentes vinham se manifestando na cobertura dos eventos. Enquanto a mídia comercial sobrevoava de helicóptero para avaliar a quantidade de manifestantes (o Jornalismo se preocupa com números) e observar pontos de confronto (o conflito é um critério de noticiabilidade), o Jornalismo colaborativo (Mídia Ninja, Agência Pública, Fora do Eixo) participava e mostrava os dados brutos da captura das informações sem edição, necessitando tão somente de um smartphone e um carregador de energia.

As jornadas de junho, como um acontecimento inserido no cotidiano das cidades carregado de potencial histórico que a atualidade reconectava com o passado, foram acompanhadas intensamente pelo Jornalismo, que lhes deu os enquadramentos possíveis: pela capacidade analítica dos jornalistas, pelos constrangimentos profissionais, pelas condições de trabalho e pelos compromissos ideológicos, as jornadas de junho se transformaram em acontecimentos jornalísticos. A questão-problema colocada por essas jornadas, a formação crítica de grande parte dos cientistas sociais, bem como as condições para publicação encurtaram a passagem do acontecimento jornalístico para o ensaio acadêmico e militante.

Além das análises que circularam nas redes sociais, logo um conjunto de publicações amplificou e renovou as análises. Muitos desses textos trataram das coberturas, incluíram ilustrações jornalísticas para suas análises que confirmaram os lugares ocupados pela mídia hegemônica e a mídia alternativa.

O livro Cidades rebeldes (ROLNIK, 2013) é um exemplo de como o mercado editorial respondeu com agilidade à análise das jornadas de junho. Com uma proposta diversificada, a longa introdução de Raquel Rolnik, As vozes das ruas: as revoltas de junho e suas interpretações, indica o objetivo da obra: interpretar o ocorrido. Mais de um texto se refere especificamente à mídia e às redes sociais. Silvia Viana, por exemplo, analisa, em particular, um programa de tevê: Brasil Urgente, apresentado por José Luiz Datena. Reproduzo o relato da autora. 
O apresentador José Luiz Datena comentava, com sua habitual indignação, as imagens de estudantes enfrentando a polícia nas ruas de São Paulo, mostradas aos seus telespectadores para apresentar a pergunta da enquete do dia. Dizendo-se chocado com a violência dos manifestantes e defendendo o direito das pessoas de bem irem e virem, perguntou: 'Você é a favor desse tipo de protesto?'. Para surpresa do apresentador, e sem saber o que fazer, ao ler os resultados também visíveis para seu público, disse: 'Até agora... a maioria... eu não sei se os caras entenderam bem a pergunta... mas a maioria está achando que esse protesto de quebrar tudo é legal'... e refez a pergunta, qualificando o tipo de protesto: 'Você é a favor de protestos violentos?... eu sou contra, eu votaria no não...'. Enfatizando sua opinião, comentou: 'Não sei não, mas eu votaria no não... eu não sou a favor de quebra-quebra, protesto porque eu acho que é vandalismo'. Inconformado com a votação negativa do seu fiel público, ele ainda tentou: 'Será que formulamos mal a pergunta? Você é a favor de protesto com baderna? Eu acho que essa seria a pergunta... Faça a pergunta do jeito que eu pedi... porque, aí, fica claro, que senão o cara não entende'. Sua audiência foi teimosa e repetiu o resultado. A solução foi tirar o tema do programa substituído por outros com mais acordo entre o apresentador e sua audiência. (VIANA, 2013, p. 54).

E foi no programa do Datena que Silvia Viana se inspirou para tratar da classificação midiática dos manifestantes: eles são baderneiros. "O protesto, que assim merece ser chamado, é, em si mesmo, violento." (p. 57). Aos baderneiros, Vianna dá outras duas classificações: os pacíficos e os pacificados.

Outros livros, como o de Maria da Glória Gohn (2014), Manifestações de Junho de 2013 no Brasil e praças dos indignados no mundo, também se dedicaram ao tema das jornadas. Eles servem de bom exemplo para observar a circulação entre os saberes em torno dos acontecimentos da vida cotidiana.

É possível verificar que cada novo acontecimento aciona a memória de outros seus iguais ou semelhantes assim como aponta para um vir a ser. É na atualidade do acontecimento que o passado e o futuro se misturam. 0 continuum se dá entre saberes, entre acontecimentos, entre atualidade, memória e devir. Entre o que foi, o que é e o que será.

\section{Referências}

BAUMAN, Zygmunt. 44 cartas do mundo líquido moderno. Rio de Janeiro: Zahar, 2010.

BAUMAN, Zygmunt. Bauman sobre Bauman. Rio de Janeiro: Zahar, 2011.

BERGANZA CONDE, María Rosa. A contribuição de Robert E. Park, o jornalista que se converteu em sociólogo, à teoria da informação. In: BERGER, Christa; MAROCCO, Beatriz (Org.). A era glacial do jornalismo: teorias da imprensa. Porto Alegre: Sulina, 2008. v. 2, p. 15-32 
BERGANZA CONDE, María Rosa. Comunicación, opinión pública y prensa en la sociología de Robert E. Park. Madrid: CIS, 2000.

BERGER, Christa. Jornadas de Junho: lições de realidade. In: SAID, Gustavo; DOURADO, Jacqueline. 0 Delírio é um desejo. Teresina: EDUFPI, 2014.

BERGER, Christa; ALMEIDA, Charles Florczak. Notícias do Brasil: o jornalismo e o tempo presente. In: Freire Filho, João; Coelho, Maria das Graças Pinto. Jornalismo, Cultura e Sociedade. Visões do Brasil Contemporâneo. Porto Alegre: Sulina, 2014.

BOURDIEU, Pierre. Coisas ditas. São Paulo: Brasiliense, 1987.

BOURDIEU, Pierre. 0 campo científico. In: ORTIZ, Renato. Pierre Bourdieu. São Paulo: Ática, 1983.

BOURDIEU, Pierre. 0 poder simbólico. Rio de Janeiro: Bertrand Brasil, 1996.

GOHN, Maria da Glória. Manifestações de junho de 2013 no Brasil e praças dos indignados no mundo. Petrópolis: Vozes, 2014.

MARTINS, José de Souza. A sociabilidade do homem simples. 2. ed. São Paulo: Contexto, 2008.

MORIN, Edgar. La internacionalidad de las revueltas estudiantiles. Notas metodológicas. In: MORIN, Edgar. Sociologia. Madrid: Editorial Tecnos, 2002. Texto original de 1968.

PARK, Robert. A notícia como forma de conhecimento: um capítulo dentro da sociologia do conhecimento. In: BERGER, Christa; MAROCCO, Beatriz (Orgs.). A era glacial do

jornalismo: teorias da imprensa. Porto Alegre: Sulina, 2008. v. 2, p. 51-70

ROLNIK, Raquel e outros. Cidades rebeldes. São Paulo: Boitempo Editorial, 2013.

SLAVOJ, Zizek. Em defesa das causas perdidas. São Paulo: Boitempo Editorial, 2011.

TODOROV, Tzvetan. Os inimigos íntimos da democracia. São Paulo: Companhia das Letras, 2012.

VIANA, Silvia. Será que formulamos mal a pergunta? In: MARICATO, E. et al. Cidades rebeldes: passe livre e as manifestações que tomaram as ruas do Brasil. São Paulo: Boitempo, 2013.

WEBER, Max. Sociologia da Imprensa: um programa de pesquisa. In: BERGER, Christa; MAROCCO, Beatriz. A era glacial do Jornalismo. Porto Alegre: Sulina, 2006. v. 1 


\title{
Journalism and Social Sciences: circulation of knowledge about the present
}

\begin{abstract}
This article is dedicated to discuss journalism and its relationship with social fields, memories and events. It presents arguments about the changes in contemporary society and demonstrates that, therefore, current news stories end up establishing itself as an object of interest of the social sciences. Addresses the understanding of the knowledge produced in journalistic discourse through social scientists interpretations and demonstrates the breadth of this fact. Materials, reports and television programs are used as resources to exemplify assessments by social scientists, especially in regard to the media conveyed about the events of June 2013.
\end{abstract}

\section{Keywords}

journalism. Social sciences. Social fields. Memories. Events.

Recebido em 14/10/2015

Aceito em 15/12/2015 